\title{
Vertebroplasty and kyphoplasty: complementary tecniques for the treatment of painful osteoporotic vertebral compression fractures
}

\author{
Vertebroplastia e cifoplastia: técnicas complementares para o \\ tratamento da fratura vertebral osteoporótica dolorosa \\ tipo compressão
}

Vertebroplastia y cifoplastia: técnicas complementarias para el tratamiento de la fractura vertebral osteoporótica dolorosa tipo compresión

\author{
Alessio Lovi ${ }^{1}$ \\ Marco Teli' \\ Alessandro Ortolina ${ }^{2}$ \\ Francesco Costa ${ }^{2}$ \\ Maurizio Fornari ${ }^{3}$ \\ Marco Brayda-Bruno 4
}

\section{ABSTRACT}

Objective: in a prospective study, we aimed to evaluate the potential use of kyphoplasty (KP) and vertebroplasty (VP) as complementary techniques in the treatment of painful osteoporotic vertebral compression fractures (VCFs). Methods: afteronemonthof conservative treatment for VCFs, patients with intractable pain were offered treatment with KP or VP according to a treatment algorithm that considers time from fracture $(\Delta t)$ andamountofVertebralBodyCollapse (VBC). Bone biopsy was obtained intraoperatively to exclude patients affected by malignancy or osteomalacia. Results: hundred and sixty-four patients were included according to the above criteria. Mean age was 67.6 years. Mean followup was 33 months. Ten patients $(6.1 \%)$ were lost to follow-up and 154 reached

\section{RESUMO}

Objetivo: estudo prospectivo para avaliar a utilização da cifoplastia e vertebroplastia como técnicas complementares para o tratamento das fraturas osteoporóticas tipo compressão. Métodos: após um mês de tratamento conservador, os pacientes com fratura osteoporótica do tipo compressão e com dor intratável, foram submetidos à cifoplastia ou vertebroplastia de acordo com algoritmo que considera o tempo da fratura e a quantidade do colapso do corpo vertebral. Biópsia óssea foi obtida no intra-operatório para excluir os pacientes com tumor ou osteomalácia. Resultados: cento e trinta e quatro pacientes foram incluídos de acordo com os critérios do estudo. A média de idade foi 67,7 anos. O seguimento médio foi 33 meses. Dezpacientesnão foram seguidose

\section{RESUMEN}

Objetivo: estudio prospectivo para evaluar la utilización de la cifoplastia $y$ vertebroplastia como técnicas complementarias para el tratamiento de las fracturas osteoporóticas tipo compresión. Métodos: después de 1 mes de tratamiento conservador, los pacientes con fractura osteoporótica del tipo compresión y de haber presentado un dolor intratable, los pacientes fueron sometidos a la cifoplastia o vertebroplastia de acuerdo con el algoritmo que considera el tiempo de la fractura y la cantidad del colapso del cuerpo vertebral. Biopsia ósea fue obtenida en el intraoperatorio para excluir los pacientes con tumor u osteomalacia. Resultados: ciento treinta y cuatro pacientes fueron incluidos de acuerdo con los criterios del estudio. El promedio de edad fue

Study carried out at Spine Surgery Department III and Neurosurgery Department IRCCS Galeazzi Orthopaedic Institute, Milano, Italy.

Spine Surgery Department III IRCCS Galeazzi Orthopaedic Institute, Milano, Italy.

${ }^{2}$ Neurosurgery Department IRCCS Galeazzi Orthopaedic Institute, Milano, Italy.

${ }^{3}$ Head of Department, Neurosurgery Department IRCCS Galeazzi Orthopaedic Institute, Milano, Italy.

${ }^{4}$ Head of Department, Spine Surgery Department III IRCCS Galeazzi Orthopaedic Institute, Milano, Italy 
the minimum two years follow-up. 118 (69.5\%) underwent VP and 36 (30.5\%) underwent KP. Complications affected five patients treated with VP, whose one suffered a transient intercostal neuropathy and four a subsequent VCF (two at adjacent level). Results in terms of VAS and Oswestry scores were not different among treatment groups. Conclusion: in conclusion, at an average follow-up of almost 3 years from surgical treatment of osteoporotic VCFs, VP and KP show similar good clinical outcomes and appear to be complementary techniques with specific different indications.

KEYWORDS: Vertebroplasty; Spinal fractures/surgery; Osteoporosis/complications; Fractures, compression/ surgery; Kyphosis/surgery; Lumbar vertebrae/surgery
154 atingiram um seguimento mínimo de dois; 118 pacientes $(69,5 \%)$ foram submetidos à vertebroplastia e $36(30,5 \%)$ à cifoplastia. Ocorreram complicações em cinco pacientse tratados por verebroplastia, sendo que um paciente apresentou neuropatia intercostal transitória e quatro pacientes fratura por compressão, tendo ocorrido na vértebra adjacente em dois pacientes. Não foi observada diferença nos escores da avaliação da dor e do questionário de Oswestry. Conclusão: após um seguimento médio de três anos foram observados resultados satisfatórios com a utilização da vertebroplastia ou cifoplastia para o tratamento das fraturas osteoporóticas por compressão. Ambas as técnicas mostraram bons resultados, de acordo com a sua indicação específica.

DESCRITORES: Vertebroplastia; Fraturas da coluna vertebral/ cirurgia; Osteoporose/ complicações; Fraturas por compressão/cirurgia; Cifose/ cirurgia; Vértebras lombares/ cirurgia
67.7 años. El seguimiento promedio fue de 33 meses. Diez pacientes no fueron seguidos y 154 llegaron a un seguimiento mínimo de dos. 118 pacientes (69.5\%) fueron sometidos a la vertebroplastia y $36(30.5 \%)$ a la cifoplastia. Complicaciones ocurrieron en cinco pacientes tratados por vertebroplastia, siendo que un paciente presentó neuropatía intercostal transitoria y cuatro pacientes una fractura por compresión en la vértebra adyacente. No fue observada diferencia entre los índices de la evaluación del dolor y del cuestionario de Oswestry. Conclusión: después del seguimiento promedio de tres años fueron observados resultados satisfactorios con la utilización de la vertebroplastia o cifoplastia para el tratamiento de las fracturas osteoporóticas por compresión. Ambas técnicas mostraron buenos resultados de acuerdo con su indicación especifica.

DESCRIPTORES: Vertebroplastia; Fracturas espinales/cirugía; Osteoporosis/complicaciones; Fracturas, compresión/cirugía; Cifosis/cirugía; Vértebras lumbares/cirugía

\section{INTRODUCTION}

Osteoporotic vertebral compression fractures (VCFs) are a major healthcare problem. Symptomatic VCFs (about $30 \%$ of all VCFs esteemed to occur in the western world) can be associated with decreased quality of life and increased mortality in the elderly ${ }^{1,2}$. Irrespective of fracture pain, disability associated with VCFs is apparently caused by changes in the alignment of the spine and related to the severity of spinal deformity ${ }^{3}$ Different approaches for the treatment of painful osteoporotic VCFs are currently available. Standard management includes bed rest, analgesia, bracing or a combination of these. Prolonged bed rest leads to further loss of bone mass, while bracing cannot restore spinal alignment and often is poorly tolerated by older patients ${ }^{4,5}$. Open surgical treatment is reserved to the rare cases of progressive deformity and neurological deterioration or to the more frequent cases of persistent intractable pain. Vertebroplasty (VP) and Kyphoplasty (KP) are well known percutaneous vertebral body augmentation procedures that provide good pain relief when used to treat osteoporotic $\mathrm{VCF}^{1,5,6}$. VP involves percutaneous injection of bone cement into the fractured vertebra/e in order to stabilise the fracture. KP involves an initial step of expansion of a balloon into the vertebral body, which creates a cavity to be filled with bone cement and allows for reduction of the fracture. VP and KP have so far been proposed as alternative $\mathrm{e}^{1,5,6}$ techniques because of the supposed possibility of KP to reduce vertebral body deformity. In fact, VP has also been reported to be able to provide some fracture reduction ${ }^{7}$. To date, a few prospective studies have reported comparative results of KP and VP in patients affected by osteoporotic $\mathrm{VCFs}^{8}$. Aim of this study is to prospectively evaluate the use of KP and VP as complementary approaches, with different indications, in the treatment of painful osteoporotic VCFs.

\section{METHODS}

The authors of the present study practice at a tertiary referral Centre for spinal disorders, where patients are seen as acute admissions to the Emergency Department, or as outpatients referred by other medical professionals. For inclusion in the present study, the authors have considered patients seen from January 2003 to January 2005 with a diagnosis of painful VCF associated with primary (senile and postmenopausal) or secondary (long term steroid use) osteoporosis ${ }^{3}$. Osteoporosis was defined as a 2.5 or more standard deviations decrease in bone mineral density at observation ${ }^{9}$, and confirmed on bone biopsy in patients who were later operated on. Patients whose bone histology did not show features of osteoporosis (osteomalacia or neoplasm) were excluded from the study. VCFs were defined as those fractures that showed a vertebral body collapse (VBC) of at least $20 \%{ }^{10}$, comparing the absolute values of three vertical body heights (anterior, mid-vertebral and posterior) of the fractured vertebra with the vertebra above ("referent" vertebra) on plain lateral radiographs ${ }^{11}$. Two-plane radiographs of the affected spinal region and Magnetic Resonance Imaging (MRI) of the whole spine were obtained in all patients at observation ${ }^{4,5,12}$. Symptomatic levels 
were identified by correlating the clinical findings (i.e. pain on pressure and tapping over the spinous processes), with MRI findings of marrow signal changes on Short Tau Inversion Recovery (STIR) sequences consistent with the presence of compression fractures at the symptomatic levels ${ }^{4,10,13}$. Minimum follow-up for evaluation of data was set at two years.

Treatment algorithm - Once the diagnosis of symptomatic osteoporotic VCF was established, patients were managed according to a specific treatment algorithm (Figure 1), designed to take into account the presence of pain, the time elapsed from fracture to observation $(\Delta t)$ and the amount of vertebral body collapse at observation. The algorithm helped to decide whether conservative or surgical treatment (VP or KP with injection of PMMA ) should be considered in a given case. This algorithm was first proposed at the IMAST meeting of the year $2003^{14}$. Conservative treatment was suggested to all patients with painful VCFs in the first month from fracture. As far as timing was concerned, minimum $\Delta$ t to consider surgical treatment (either with VP or KP) was 1 month from fracture, while maximum $\Delta t$ to consider surgical treatment with $\mathrm{KP}$ was 3 months due to the reported difficulties in reducing VCFs after this time interva ${ }^{13,4,15}$. As far as deformity was concerned, VP was considered in case of fracture deformity less than $30 \%$, while KP was considered in case of VBCs equal or higher than $30 \%$. As a result, surgical treatment with VP was offered to patients with persistent pain due to VCFs with vertebral collapse less than $30 \%$ and a $\Delta$ t longer than 1 month, or a $\Delta t$ longer than 3 months with any amount of fracture deformity. KP was offered to patients with persistent pain due to VCFs with vertebral collapse equal or higher than $30 \%$ and $\mathrm{a} \Delta \mathrm{t}$ between 1 and 3 months.

Patients included into the study were entered into a prospective cohort database and managed according to the above-described criteria. Conservative treatment consisted of a period of relative bed rest and analgesia, with the application of a thoraco-lumbar extension orthosis while standing ${ }^{10}$.
Length of bed rest was restricted to that necessary to achieve a reasonable control of pain at mobilization. Those patients who were improved after one month were followed by family GP. Patients who were still reporting severe pain were then referred to surgical treatment. This was performed as an inpatient procedure in case of both for VP and for KP. VP was performed under local anaesthesia and intravenous sedation in patients affected by one fracture, and under general anaesthesia in patients affected by more than one fracture to be treated in the same session ${ }^{5}$ KP was always performed under general anaesthesia. The surgical techniques did not differ from those already described for VP and KP with PMMA ${ }^{6,17-19}$ and, except for the use of the inflatable bone tamp in KP, with identical cannulae and PMMA density. Patients were mobilised as soon as tolerated on the same day of surgery and discharged on the following day.

Follow-up was performed at 1 month, 3 months, and 6 months and at a minimum of 2 years from treatment. The clinical results in all patients were evaluated by comparing preoperative and follow-up data from a Visual Analogue Scale (VAS) and na Oswestry Disability Index (ODI) 2.0 questionnaire. On plain lateral radiographs, the anterior, mid-vertebral and posterior $\mathrm{VBC}$ was calculated in percentage comparing the absolute value of the anterior, mid-vertebral and posterior vertical heights of the treated vertebra with the vertebra above ("referent vertebra") in all patients.

For statistical analysis, preoperative and follow-up VAS, ODI scores and radiographic vertebral height values were compared using Student's paired $t$ test by means of a SPSS program (SPPS Inc, Chicago IL, USA). Differences between groups were evaluated by the Fisher's exact test. Correlations were investigated via Pearson's analysis. For all comparisons, a p value of less than 0.05 (two-tailed) was considered significant. Three observers made radiographic measurements independently. Intra-observer and interobserver reliability were assessed using the kappa statistic.

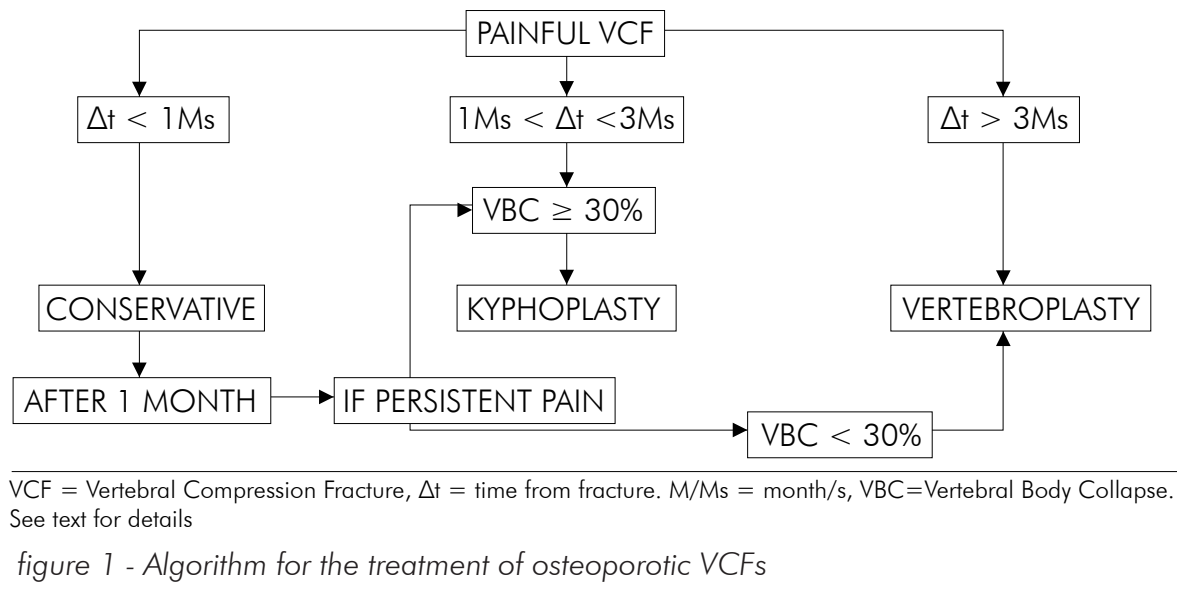

\section{RESULTADOS}

Out of 314 patients suffering symptomatic, osteoporotic VCFs seen consecutively in the study period, 164 patients were included in the study cohort according to the abovedescribed criteria and 150 were treated conservatively. Ten patients $(6.1 \%)$ were excluded because they were lost to follow-up. Patients included had records of follow-up consultations and radiograms made at the above described intervals until a minimum of two years from fracture. Out of the 154 enrolled patients who were treated surgically, $49(31.8 \%)$ had initially been treated conservatively. Furthermore, in 16 (32.6\%) of those patients with an initial 
VBC of less than $30 \%$, VBC deteriorated to more than $30 \%$ after one month. Out of 154 surgical patients, $118(69.5 \%)$ underwent VP (VP Group) and 36 (30.5\%) underwent KP (KP Group). In this cohort composed of 98 women and 56 men, mean age was 67.6 years (range, 53 to 95 years) and mean follow-up was 33 months (range, 28 to 40 months). Gender distribution, age and follow-up time did not differ significantly among the two surgical groups.

Hundred and ninety-nine fractured levels were operated in total. The number of levels treated per surgery was 1.86 on average (range, 1 to 4). In 104 out of 154 patients $(67,5 \%)$ surgical treatment was performed at multiple levels. Two of these patients had staged procedures that were analysed independently. The levels treated ranged from T7 to L5, with $84(42.2 \%)$ thoracic and 115 (57.8\%, $\mathrm{p}<0.05)$ lumbar treated levels. The mean $\Delta \mathrm{t}$ was 4 months (122 days; range, 44-240 days) in VP Group and 1.5 months (46 days; range, 34-91 days, $\mathrm{p}=0.01$ ) in KP Group. Both VP and KP were performed via a trans-pedicular approach for levels caudal to T10 and via an extrapedicular approach for levels cranial to T10. On average, $2.5 \mathrm{ml}$ of PMMA were normally injected per vertebra in VP procedures, compared to $3.2 \mathrm{ml}$ per vertebra in $\mathrm{KP}$ $(p>0.05)$. The average procedure time per level was 15 minutes (range, 10 to 30 minutes) for VP and 25 minutes (range, 15 to 40 minutes, $\mathrm{p}=0.01$ ) for KP. Mean hospital stay was 2.0 days (range, 1 to 2 days) for VP and 2.2 days (range, 1 to 3 days) for $\mathrm{KP}$ ( $\mathrm{p}>0.05)$.

TABLE 1 - Main clinical data

\begin{tabular}{llllll}
\hline VAS (mean) & Baseline & 1month & 3months & 6months & 24months \\
\hline VP Group & 8.4 & $3.6^{*}$ & 3.2 & 3 & 2 \\
KP Group & 8 & $3.4^{*}$ & 3 & 2.6 & 1.9 \\
ODI(mean) & & & & & \\
VP Group & 52.3 & $23^{* \circ}$ & $12.7^{*}$ & 8.5 & 6.7 \\
KP Group & 49.1 & $22.1^{* \circ}$ & $13.1^{*}$ & 7.2 & 4.8 \\
\hline
\end{tabular}

${ }^{*} p<0.05$ compared to value on left column, Student's $t$ test ` $p<0.05$ compared to Group 1 on same column, Fisher's Test

\section{TABLE 2 - Main radiographic data}

Anterior VBC Preoperative Postoperative 3months 6months 24months

(mean \pm SD)

$\begin{array}{llllll}\text { VP Group } & 21 \pm 2 \% & 21 \pm 1 \% & 20 \pm 3 \% & 20 \pm 3 \% & 21 \pm 3 \% \\ \text { KP Group } & 39 \pm 3 \% & 32 \pm 2 \% * & 33 \pm 3 \% & 33 \pm 2 \% & 34 \pm 3 \%\end{array}$

Midline VBC

$($ mean $\pm \mathrm{SD})$

$\begin{array}{llllll}\text { VP Group } & 19 \pm 1 \% & 20 \pm 2 \% & 20 \pm 2 \% & 19 \pm 1 \% & 19 \pm 2 \% \\ \text { KP Group } & 37 \pm 4 \% & 30 \pm 3 \% * & 30 \pm 3 \% & 31 \pm 2 \% & 31 \pm 3 \% \\ \text { Posterior VBC } & & & & & \\ \text { (mean } \pm \text { SD) } & & & & & \\ \text { VP Group } & 9 \pm 2 \% & 10 \pm 2 \% & 10 \pm 2 \% & 9 \pm 1 \% & 9 \pm 1 \% \\ \text { KP Group } & 12 \pm 2 \% & 10 \pm 2 \% & 10 \pm 2 \% & 11 \pm 2 \% & 11 \pm 1 \%\end{array}$

$\mathrm{VBC}=$ vertebral body collapse

${ }^{*} p<0.05$ compared to value on left column, Student's t test
Table 1 summarises the clinical results in the treatment groups. In VP Group, mean VAS scores decreased significantly $(\mathrm{p}<0.05)$ between preoperative and one month follow-up. Pain relief was complete (VAS $=0$ ) in 22 out of 118 cases $(18.6 \%)$ at the first month follow-up and continued to decrease non-significantly until the last follow-up. In KP Group, VAS scores decreased significantly $(\mathrm{p}<0.05)$ between preoperative and one month followup and behaved similarly to VP Group for the rest of the follow-up period. Pain relief was complete $(\mathrm{VAS}=0)$ in 6 out of 36 cases $(16.6 \%, p>0.05$ compared to VP Group) at the first month follow-up. ODI scores had a similar trend to that of VAS scores in all groups, with significant decreases between preoperative and one month follow-up. ODI scores improved significantly in all groups still at the three-month follow-up and later showed a slow, nonsignificant improvement distributed throughout the followup period. ODI scores were also significantly higher in both surgical groups compared to the conservative group at the first month follow-up only. Clinical results were not significantly different after stratification of the number of levels treated per patient, either with VP or KP.

Radiographic measurements (Table 2) showed that at one month follow-up, no significant height restoration was observed in 110 out of $156(70.5 \%)$ vertebral levels treated with VP, while in 46 vertebrae $(29.5 \%)$ the measurements of vertebral body height showed mild but significant differences for anterior height restoration $(5 \%, \mathrm{p}<0.05)$ and mid-vertebral height restoration $(5 \%, \mathrm{p}<0.05)$ (Figures $1 \mathrm{~A}-\mathrm{C})$.
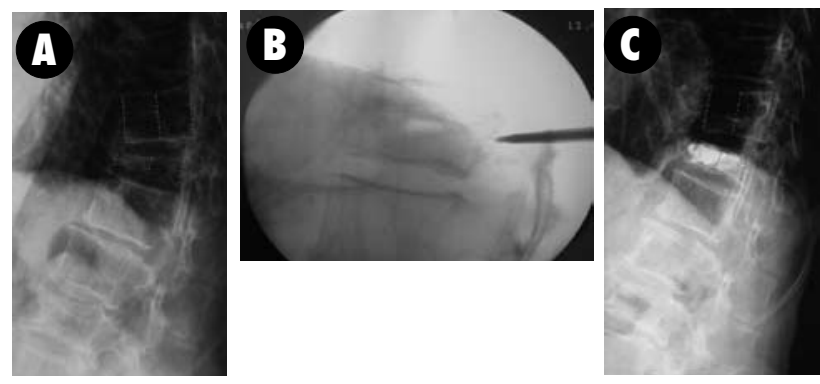

Figure 1

(A) Preoperative; (B) 36 months follow-up;

(C) Lateral radiographs showing improvement of anterior VBC following vertebroplasty at T12

In KP Group, mean anterior VBC was higher than mean mid-vertebral and posterior $\mathrm{VBC}$ at observation. After one month, the measurements of vertebral body height showed mild but significant differences for anterior height restoration $(7 \%, \mathrm{p}<0.05)$ and mid-vertebral height restoration $(7 \%, \mathrm{p}<0.05)$ (Figures $2 \mathrm{~A}-\mathrm{C}$ ). On the other hand, in 10 out of 43 $(23.2 \%)$ vertebral levels treated with KP, there was no measurable height restoration. Analysis of height restoration in VP and KP Group did not show statistical differences between thoracic and lumbar levels. For radiographic measurements, $\mathrm{K}$ values for intra-observer agreement were excellent (0.79) and for interobserver agreement were good (0.70). No significant correlation was found in any group between VAS or ODI scores and radiographic measurements. 

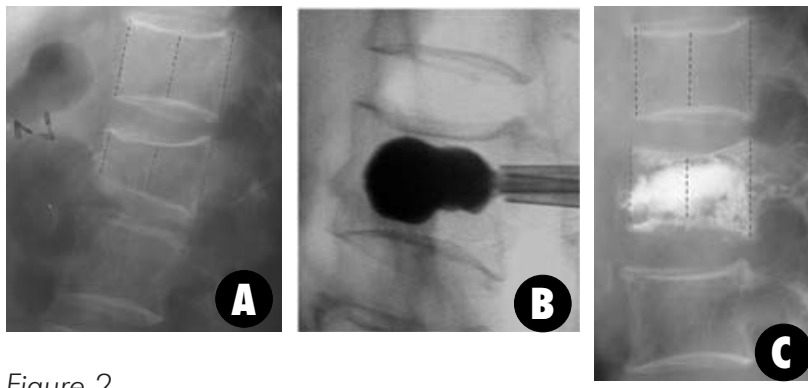

Figure 2

(A) Preoperative; (B) 36 months follow-up; (C) Lateral radiographs showing improvement of anterior VBC following kyphoplasty at L2

Complications - Cement leakage outside the vertebral body was observed in 29 out of 199 vertebrae (14.6\%). The site of leakage was the adjacent disk in 14 levels (10 treated by VP and 4 by KP, $\mathrm{p}<0.05)$, the peri-vertebral veins in 9 levels $(7$ treated by VP and 2 by KP, $p<0.05)$ and the epidural space in a single case of VP. The last occurred in a woman who underwent a VP at T8. After the procedure the patient developed intercostal neuralgia. A postoperative computedtomographyscanshowedextravasationsofcement into the epidural space and right neuroforamen. I.v. and oral analgesia helped to control the neuropathic pain, which eventually resolved in three months. 4 patients in VP Group suffered subsequent VCF (two at adjacent level) a mean time of 9 months after the index procedure. These fractures were initially treated conservatively for the first month, but two patient required VP because of persisting pain. One patient died 7 months after VP, because of a pre-existing chronic obstructive pulmonary disease.

\section{DISCUSÃO}

The necessity of an algorithm for the treatment of such a frequent disease as a painful osteoporotic VCF is based on the lack of consensus regarding the proper surgical indications, i.e. timing, application and effectiveness of the percutaneous vertebral body augmentation techniques ${ }^{4,10,15}$. Although VP and KP are currently well diffused into clinical practice and generally considered as alternative techniques based on different philosophy of treatment, their role compared to conservative treatment is still controversial ${ }^{10,15}$. This is because many patients report only mild and transient symptoms, with significant improvement in the first month of conservative care. The analysis of the current literature is confusing as far as the most appropriate timing of application of VP and KP is concerned. On the one hand it is suggested that VP should be considered after a course of 3 months of conservative treatment2. On the other, supporters of KP suggest the procedure should be done within three months from fracture to increase the likelihood of a favourable outcome ${ }^{16}$, or even within a few days from fracture to achieve a good restoration of vertebral height ${ }^{17}$. However, in a recent prospective series ${ }^{20}$ patients treated with KP had chronic pain of more than 12 months duration and still there were improvements in vertebral body height, pain and mobility compared to the preoperative status. The authors of the present study, in accordance with others, believe that one month is the minimum waiting period before considering surgery because of the natural history of osteoporotic VCFs and the higher risk of cement leakage within the first month from fracture ${ }^{10,15}$.

We then suggest that after 1 month of failed conservative treatment, VP must be considered for persistent painful fractures with a $\mathrm{VBC}$ less than $30 \%$, whereas $\mathrm{KP}$ is considered for fractures that had progressed to a vertebral body collapse equal or higher than $30 \%$ within the third month(Figure 1). KP must be performed earlier than 3 months in order to maximise the possibility of improvement in spinal sagittal alignment ${ }^{4,21}$. This matter leads to the controversy that has arisen around the most appropriate fracture to be treated with VP versus KP. In fact, both techniques are able to provide dramatic pain relief in appropriately selected patients. It is also evidenced by the recent literature that both VP and KP are able to produce partial restoration of vertebral body heights. This effect might be due to patient positioning in both techniques, and to the direct mechanical effect of the balloon inflation in $\mathrm{KP}^{10,21}$. In our series, a significant increase in mid-vertebral body heights was observed in both groups, but these data were not correlated with a different outcome in terms of VAS and ODI scores. It has recently been suggested that reduction of vertebral body compression fracture has no real influence on the overall sagittal alignment5. Although the higher costs of KP compared to VP15 must be considered, our five years experience shows that in a case-mix analysis also the cost of these procedures, according to the $\mathrm{VP} / \mathrm{KP}$ ratio reported in the present study (118/36), is more than reasonable in all reimbursement systems. In our cohort of surgically treated patients, VAS and ODI values improved in all Groups with minimal differences (Tables 1 and 2), while the number of levels treated per patient was not a predictor of outcomes of either VP or KP.

The main reported risk of VP and KP is extra-vertebral cement leakage. This is due to cement leaking through cortical defects or to injection of cement into the draining vertebral venous plexus. Cement leakage with clinical consequences has been reported with both VP and KP.

Complications due to cement leakage have included pulmonary embolism, mediastinitis, neuropathic pain and paraplegia among others. VP has a higher reported incidence of cement leakage than $\mathrm{KP}^{4,10,15,22}$, as confirmed also by the present study. In order to decrease the risk of cement leakage, we decided to perform VP with cannulae (using more dense cement) and only after 4 weeks from fracture, as reported by several other authors ${ }^{10,21,22}$. This has possibly helped to maintain a low rate of neurological complications in the present series ( 1 out of 154 patients or $0.6 \%$ ) with lower rate of cement leaks than reported in the previous literature ${ }^{13,23-25}$.

The fracture rate at adjacent level was low (4 out of 154 patients or $2.5 \%$ ) in this series at 2 years follow-up, well comparing with other authors' series ${ }^{3,15,21}$. It is not clear whether injection of acrylic cement might favour fractures at adjacent levels at a higher rate than that caused by the underlying osteoporosis itself, especially at a longer followup. Also, it is unclear whether different amounts of injected cement might influence the stiffness of the treated vertebra and the clinical outcome ${ }^{10}$. 


\section{CONCLUSÃO}

From the experience madewith this algorithm the following conclusions could be drawn. Firstly, the reduction by KP of severely collapsed and painful VCFs provides similar pain relief and function scores to that occurring with VP applied to less severe VCFs. Secondly, KP shows a significantly lower risk of cement extra-vasation and then eventual major neurological complications. The higher costs of KP compared to VP could have negative impact in promoting KP as the sole treatment of painful osteoporotic VCFs, while in our experience applying the treatment algorithm, the case-mix analysis of the VP/KP ratio shows affordable costs in all reimbursement systems. The improvement seen in the clinical outcome scores is due to a strict selection criteria for both VP and KP and to a consistent surgical technique applied by trained surgeons (cannulae and dense cement). Finally, the rationale application of the above described algorithm could effectively help to address the best treatment option for any single patient affected by painful osteoporotic VCFs.

\section{REFERÊNCIAS}

1. Hall SE, Criddle RA, Comito TL, Prince RL. A case-control study of quality of life and functional impairment in women with longstanding vertebral osteoporotic fracture. Osteoporos Int. 1999;9(6):508-15.

2. Leidig-Bruckner G, Minne HW, Schlaich C, Wagner G, Scheidt-Nave C, Bruckner $\mathrm{T}$, et al. Clinical grading of spinal osteoporosis: quality of life components and spinal deformity in women with chronic low back pain and women with vertebral osteoporosis. J Bone Miner Res. 1997;12(4):663-75.

3. Lieberman IH, Dudeney S, Reinhardt MK, Bell G. Initial outcome and efficacy of "kyphoplasty" in the treatment of painful osteoporotic vertebral compression fractures. Spine. 2001;26(14):1631-8.

4. Garfin SR, Yuan HA, Reiley MA. New technologies in spine: kyphoplasty and vertebroplasty for the treatment of painful osteoporotic compression fractures. Spine. 2001;26(14):1511-5.

5. Pradhan BB, Bae HW, Kropf MA, Patel VV, Delamarter RB. Kyphoplasty reduction of osteoporotic vertebral compression fractures: correction of local kyphosis versus overall sagittal alignment. Spine. 2006;31(4):435-41.

6. Deramond H, Depriester C, Galibert P, Le Gars D. Percutaneous vertebroplasty with polymethylmethacrylate. Technique, indications, and results. Radiol Clin North Am. 1998;36(3):53346.

7. Hulme PA, Krebs J, Ferguson SJ, Berlemann U. Vertebroplasty and kyphoplasty: a systematic review of 69 clinical studies. Spine. 2006;31(17):1983-2001.

8. Grohs JG, Matzner M, Trieb K, Krepler P. Minimal invasive stabilization of osteoporotic vertebral fractures: a prospective nonrandomized comparison of vertebroplasty and balloon kyphoplasty. J Spinal Disord Tech. 2005;18(3):238-42.

9. Matthis C, Weber U, O’Neill TW, Raspe H. Health impact associated with vertebral deformities: results from the European Vertebral Osteoporosis Study (EVOS). Osteoporos Int. 1998;8(4):364-72.

10.Rao RD, Singrakhia MD. Painful osteoporotic vertebral fracture. Pathogenesis, evaluation, and roles of vertebroplasty and kyphoplasty in its management. J Bone Joint Surg Am. 2003;85-A(10):2010-22.

11. Mehbod A, Aunoble S, Le Huec JC. Vertebroplasty for osteoporotic spine fracture: prevention and treatment. Eur Spine J. 2003;12 Suppl 2:S155-62.

12. Franck H, Boszczyk BM, Bierschneider M, Jaksche H. Interdisciplinary approach to balloon kyphoplasty in the treatment of osteoporotic vertebral compression fractures. Eur Spine J. 2003;12 Suppl 2:S163-7.

13. Cyteval C, Sarrabère MP, Roux JO, Thomas E, Jorgensen C, Blotman F, et al. Acute osteoporotic vertebral collapse: open study on percutaneous injection of acrylic surgical cement in 20 patients. AJR Am J Roentgenol. 1999;173(6):1685-90.

14.Brayda-Bruno M, Lovi A, Marinoni EC. Vertebroplasty and kyphoplasty. algorithm for the treatment of painful osteoporotic vertebral compression fractures In:10th International Meeting on Advanced Spine Techniques (IMAST); 2003 July; Rome, Italy.

15.Mathis JM, Ortiz AO, Zoarski GH. Vertebroplasty versus kyphoplasty: a comparison and contrast. AJNR Am J Neuroradiol. 2004;25(5):840-5.++

16.Hardouin P, Fayada P, Leclet H, Chopin D. Kyphoplasty. J Bone Spine. 2002;69(3):256-61.

17.Heini PF, Orler R. Kyphoplasty for treatment of osteoporotic vertebral fractures. Eur Spine J. 2004;13(3):18492.

18.Legroux-Gérot I, Lormeau C, Boutry N, Cotten A, Duquesnoy B, Cortet B. Longterm follow-up of vertebral osteoporotic fractures treated by percutaneous vertebroplasty. Clin Rheumatol. 2004;23(4):310-7.
19.McKiernan F, Faciszewski T, Jensen $\mathrm{R}$. Reporting height restoration in vertebral compression fractures. Spine. 2003;28(22):2517-21.

20.Kasperk C, Hillmeier J, Nöldge G, Grafe IA, Dafonseca K, Raupp D, et al. Treatment of painful vertebral fractures by kyphoplasty in patients with primary osteoporosis: a prospective nonrandomized controlled study. J Bone Miner Res. 2005;20(4):604-12.

21.Phillips FM. Minimally invasive treatments of osteoporotic vertebral compression fractures. Spine. 2003;28(15 Suppl):S45-53.

22.Phillips FM, Todd Wetzel F, Lieberman I, Campbell-Hupp M. Na in vivo comparison of the potential for extravertebral cement leak after vertebroplasty and kyphoplasty. Spine. 2002;27(19):2173-8.

23.Berlemann U, Franz T, Orler R, Heini PF. Kyphoplasty for treatment of osteoporotic vertebral fractures: a prospective non-randomized study. Eur Spine J. 2004;13(6):496-501.

24.Cortet B, Cotten A, Boutry N, Flipo RM, Duquesnoy B, Chastanet P, et al. Percutaneous vertebroplasty in the treatment of osteoporotic vertebral compression fractures: na open prospective study. J Rheumatol. 1999;26(10):2222-8.

25.Heini PF, Wälchli B, Berlemann U. Percutaneous transpedicular vertebroplasty with PMMA: operative technique and early results. A prospective study for the treatment of osteoporotic compression fractures. Eur Spine J. 2000;9(5):445-50.

\section{Correspondência}

Marco Teli

Via Galeazzi 4, 20161 Milano, Italy

Tel/fax +390266214911

E-mail: marcoteli@hotmail.com 